\title{
Importance of Hydro Power
}

\author{
Reshmi Banerjee
}

Ph. D Student, Department of Business Management, Calcutta University, Kolkata, India

\begin{abstract}
Hydro power or water power is power derived from the energy of falling water or fast running water, which may be harnessed for useful purposes. In the late $19^{\text {th }}$ century, hydropower became a source for generating electricity. Hydropower is the most important and widely used renewable source of power. Hydropower represents about $16 \%$ of total electricity production. The hydro power reserves of India have been estimated by the Central Water and Power Commission. It is estimated that there is potential for installing $411180 \mathrm{MW}$. In hydro power plants energy of water is utilised to move the turbines which in turn run the electric generators. The energy of water utilised for power generation may be kinetic or potential. Earlier hydroelectric plants have been used as exclusive source of power, but the trend is towards use of hydropower in an interconnected system with thermal stations.
\end{abstract}

Keywords: Conduit hydroelectricity, Hushing, Hydropower, Pumped storage hydroelectricity, Run-off-the river hydroelectricity.

\section{INTRODUCTION}

Since ancient times, hydropower from many kinds of First hydro power station was probably started in America watermills has been used as a renewable energy source for in 1882 and thereafter development took place very irrigation and the operation of various mechanical devices, rapidly. In India the first major hydropower development such as gristmills, sawmills, textile mills, trip hammers, of $4.5 \mathrm{MW}$ capacity named as Sivasamudram Scheme in dock cranes, domestic lifts, and ore mills. In India, water Mysore was commissioned in 1902. In 1914 a hydropower wheels and watermills were built, in Imperial Rome, water plant named Khopali project of 50 MW capacity was powered mills produced flour from grain, and were also used for sawing timber and stone; in China, watermills were widely used since the Han dynasty in China and the rest of the Far East, hydrautically operated "pot wheel" pumps raised water into crap or irrigation canals.

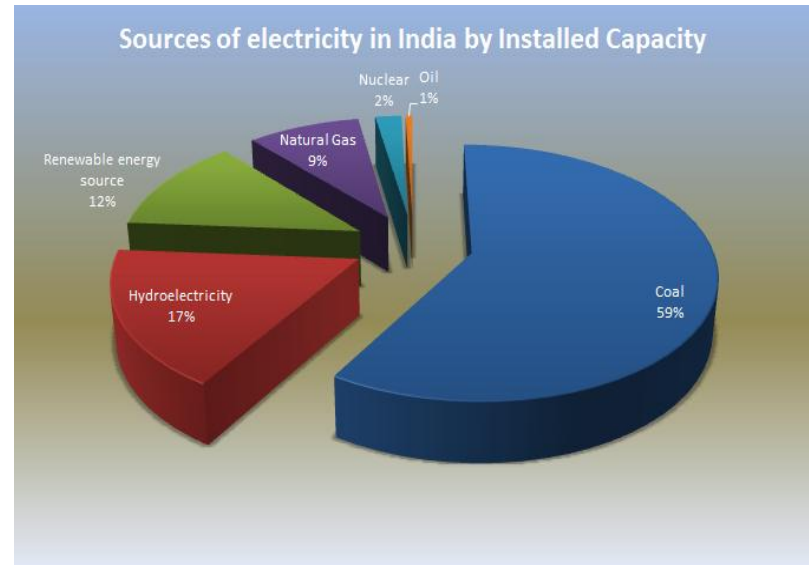

Fig. 1: Sources of electricity in India by installed capacity

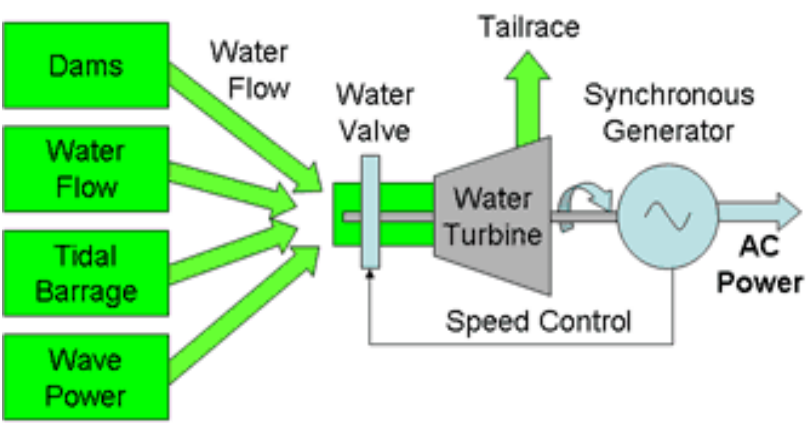

Hydro Electric Power Generation

Fig. 2: Hydro electric power generation commissioned in Maharashtra. The hydropower capacity, up to 1947 , was nearly $500 \mathrm{MW}$.

The following factors are major obstacles in the utilisation of hydropower resources:

- Large investments.

- Long gestation period.

- Increased cost of power transmission.

The following factors should be considered while selecting the site for a hydro power plant:

- Availability of water

- Water storage

- Water head

- Accessibility of the site

- Distance from load centre

- Type of the land of site

Availability of water - The most important aspect of hydro power plant is the availability of water at the site since all other designs are based on it. Therefore the run-off data at the proposed site must be available beforehand. It may not be possible to have run-off data at the proposed site but data concerning the rainfall over the large catchment area is always available. Estimate should be made about the average quantity of water available throughout the year and also about maximum and minimum quantity of water available during the year. These details are necessary to:

(i) Decide the capacity of the hydro power plant,

(ii) Setting up of peak load plant such as steam, diesel or gas turbine plant and to,

(iii) Provide adequate spillways or gate relief during the flood period.

Water storage - Since there is a wide variation in rainfall during the year, therefore, it is always necessary to store the water for continuous generation of power. The storage 
capacity can be calculated with the help of mass curve. Maximum storage should justify the expenditure on the project.

The two types of storages in use are:

$>$ The storage is so constructed that it can make water available for power generation of one year only. In this case storage becomes full in the beginning of the year and becomes empty at the end of each year.

$>$ The storage is so constructed that water is available in sufficient quantity even during the worst dry periods.

Water head - In order to generate a requisite quantity of power it is necessary that a large quantity of water at a sufficient head should be available. An increase in effective head, for a given output, reduces the quantity of water required to be supplied to the turbines.

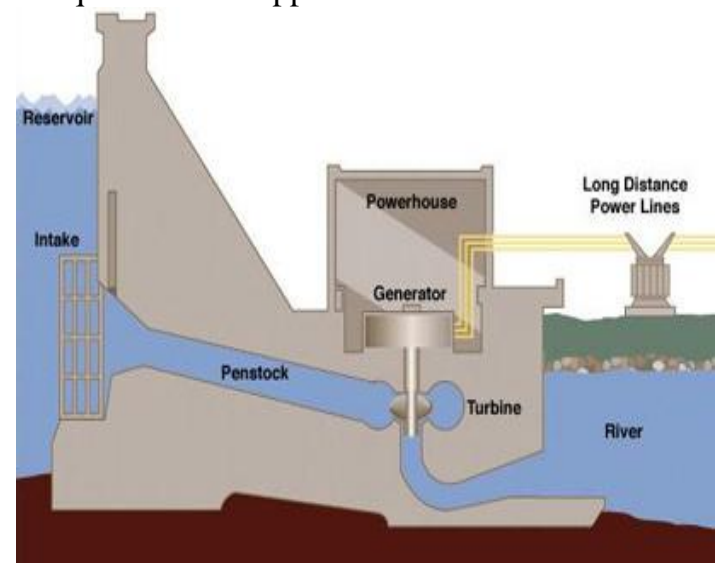

Fig. 3: Parts of Hydropower plant

Accessibility of the site - The site where hydro power plant is to be constructed should be easily accessible. This is important if the electric power generated is to be utilised at or near the plant site. The site selected should have transportation facilities of rail and road.

Distance from the load centre - It is of paramount importance that the power plant should be set up near the load centre; this will reduce the cost of erection and maintenance of transmission line.

Type of the land of the site -The land to be selected for the site should be cheap and rocky. The ideal site will be one where the dam will have largest catchment area to store water at high head and will be economical in construction.

The following are the essential elements of hydro power plant:

i) Catchment area

ii) Reservoir

iii) Dam

iv) Spillways

v) Conduits

vi) Surge tanks

vii) Prime movers

viii) Draft tubes

ix) Power-house and equipment

The initial cost of any hydro power plant is very high but the power produced by it is the cheapest. The following costs are included in development of a hydro power plant:

- Cost of land and riparian rights.
- Cost of railways and highways required for the construction work.

- Cost of construction.

- Cost of engineering supervision of the project.

- Cost of building etc.

- Cost of equipment.

- Cost of equipment used for power transmission.

\section{METHODOLOGY}

The power of a wave of water released from a tank was used for extraction of metal ores in a method known as hushing.

The most common type of hydropower plant uses a dam on a river to store water in a reservoir. Water released from the reservoir flows through a turbine, spinning it, which in turn activates a generator to produce electricity. But hydroelectric power doesn't necessarily require a large dam. Some hydroelectric power plants just use a small canal to channel the river water through a turbine.

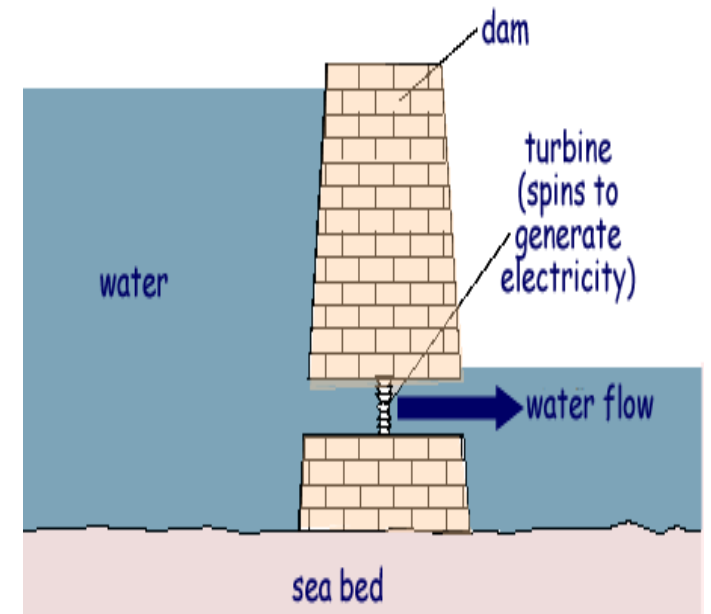

Fig. 4: Turbine spins to generate electricity

Another type of hydroelectric power plant - called a pumped storage plant - can even store power. The power is sent from a power grid into the electric generators. The generators then spin the turbines backward, which causes the turbines to pump water from a river or lower reservoir to an upper reservoir, where the power is stored. To use the power, the water is released from the upper reservoir back down into the river or lower reservoir. This spins the turbines forward, activating the generators to produce electricity.

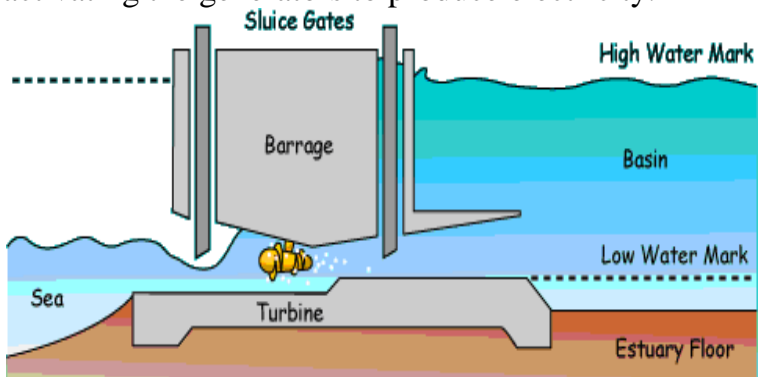

Fig. 5: Relationship between sea, turbine, basin, barrage and sluice gates

A hydropower resource can be evaluated by its available power. Power is a function of the hydraulic head and 
rate of fluid flow. The head is the energy per unit weight (or unit mass) of water. The static head is proportional to the difference in height through which the water falls. Dynamic head is related to the velocity of moving water. Each unit of water can do an amount of work equal to its weight times the head.

$>$ The available from falling water can be calculated from the flow rate and density of water, the height of fall, and the local acceleration due to gravity. In SI units, the power is :

$$
\mathrm{P}=n \mathrm{pQgh}
$$

Where, $\mathrm{P}$ is power in watts.

$\eta$ is the dimensionless efficiency of the turbine.

$\mathrm{p}$ is the density of water in kilograms per cubic metre.

$\mathrm{Q}$ is the flow in cubic metres per second.

$\mathrm{g}$ is the acceleration due to gravity.

$\mathrm{h}$ is the height difference between inlet and outlet in metres.

\section{RESULT}

- Conventional hydroelectric, referring to hydroelectric dams.

- Run-off-the-river hydroelectricity, which captures the kinetic energy in rivers or streams, without a large reservoir and sometimes without the use of dams.

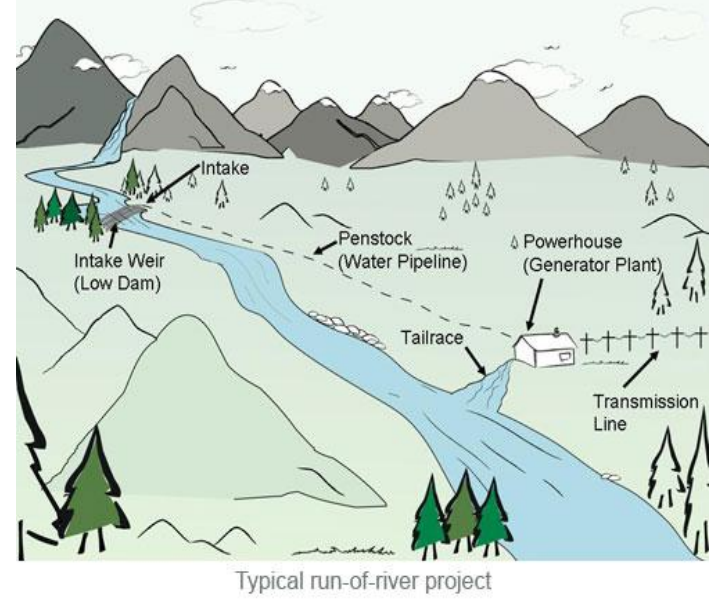

Fig. 6: Run-off-river power plant

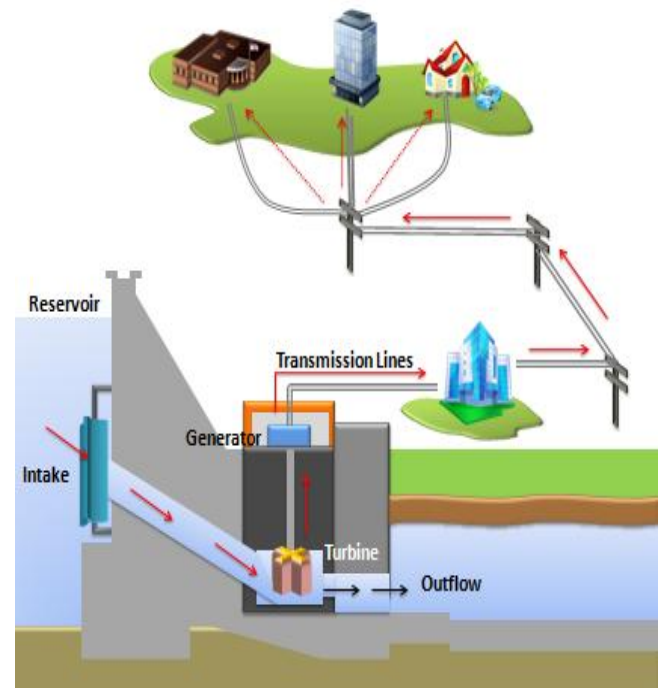

Fig. 7: How hydroelectricity is transmitted
- Small hydro projects are 10 megawatts or less and often have no artificial reservoirs.

- Micro hydro projects provide a few kilowatts to a few hundred kilowatts to isolated homes, villages, or small industries.

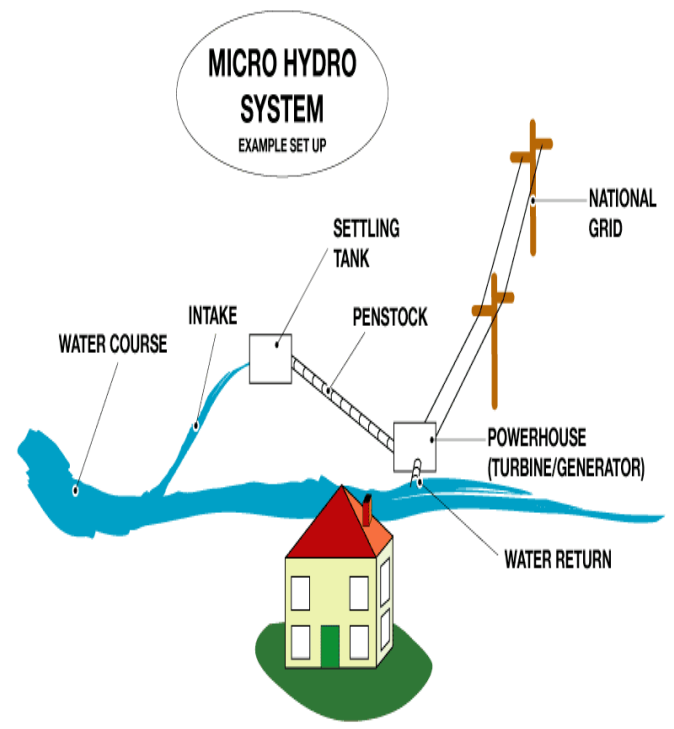

Fig. 8: Micro hydro system

- Conduit hydroelectricity projects utilize water which has already been diverted for use elsewhere, in a municipal water system, for example.

- Pumped storage hydroelectricity stores water pumped uphill into reservoirs during periods of low demand to be released for generation when demand is high or system generation is low.

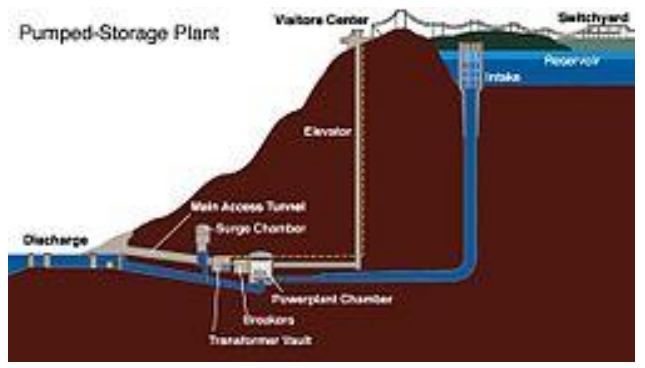

Fig. 9: Pumped storage plant

- For more than 100 years, hydropower has been an important source of flexible, low cost and emissions friendly renewable energy.

- Fuel is not burned so there is minimal pollution.

- Water to run the power plant is provided free by nature.

- Relatively low operations and maintenance costs.

- The technology is reliable and proven over time.

- If electricity is not needed, the sluice gates can be shut, stopping electricity generation. The water can be saved for use another time when electricity demand is high.

- Dams are designed to last many decades and so can contribute to the generation of electricity for many years/decades.

- The lake that forms behind the dam can be used for water sports and leisure/pleasure activities. Often large dams become tourist attractions in their own right.

- Compared to among others fossil fuels and nuclear energy, hydroelectricity is much safer. 
- The plant efficiency does not change with age.

\section{CONCLUSION}

China is the largest producer of hydropower, followed by Canada, Brazil and the United States. In some cases, there are changes in reservoir and stream water quality. Electricity generation and energy prices related to how much water is available. A drought could potentially affect this. Loss during transmission is very high, sometimes up to $30 \%$.

\section{REFERENCES}

1] R .K. Rajput, Non- Conventional Energy Sources and Utilisation, S. Chand

[2] S. A. Abbasi, NaseemaAbbasi, Renewable Energy Sources and Their Environmental Impact, PHI.

[3] S. Hasan Saeed, D. K. Sharma, Non-Conventional Energy Resources, Katson Books.

[4] S P Sukhatme, Solar Energy, Tata McGraw-Hill.

[5] David Elliot, Energy, Society \& Environment: Technology for a sustainable future, Brookings Institution Press.

[6] G. D. Rai, Non Concentional Energy Sources, Khanna Publishers.

[7] Bansal Keemam, Meliss, Renewable Energy Sources and Conversion Technology, Tata McGraw Hill.

[8] Ashok V. Desai, Non- Conventional Energy, New Age International Publishers Ltd.

[9] D. P. Kothari, Renewable Energy Resources and Emerging Technologies, Prentice Hall of India Pvt. Ltd.

[10] D. S. Chauhan, Non- Conventional Energy Resources, New Age International Limited.

[11] Dr. R. K. Singal, Non-Conventional Energy Resources, Kataria Sons.

[12] B H Khan, Non-Conventional Energy Resources, Tata McGraw Hill.

\section{BIOGRAPHY}

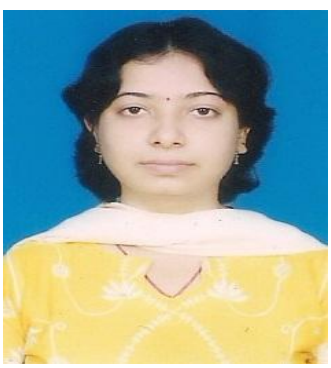

Reshmi Banerjee Passed

MadhyamikPariksha from Christ Church Girls' High School in 1998, Higher Secondary from Dum Dum Motijheel Girls' Higher Secondary School in 2000, Diploma in Electrical Engineering from Jnan Chandra Ghosh Polytechnic 2003, B. Tech from WBUT in 2006.

Completed M. Tech from Calcutta University in 2009. Pursuing Ph. D from Calcutta University. Have 9 years of teaching experience and 1 year of industrial experience. Published 22 International Journal papers and 1 International Conference paper. 